\title{
Observations
}

\author{
W. J. JACOBS \\ University of Lethbridge, Lethbridge, Alberta, Canada
}

and

\begin{abstract}
JAMES R. BLACKBURN, M. BUTTRICK, TIMOTHY J. HARPUR, D. KENNEDY, MICHAEL J. MANA, M. A. MACDONALD, LESLIE M. MCPHERSON, DENNIS PAUL, and JAMES G. PFAUS

University of British Columbia, Vancouver, British Columbia, Canada
\end{abstract}

\begin{abstract}
A basic assumption of the behavioral sciences is that there exists a direct, self-evident relationship between the behavioral categories, or types, used to describe behavior and how the organism actually behaves. This assumption is challenged. It appears that behavioral types are typically created a priori, either with an eye to convenience of measurement or on the basis of anthropomorphic or intuitive inferences. Furthermore, it appears that human observers do not record behavioral types accurately or consistently. The elementary units, or tokens, of behavior are not recorded and, therefore, play no explicit role in the creation of the types used to describe behavior. It is suggested that behavior be described explicitly through the use of formal notation systems. This suggestion is supported by a review of studies that have used such systems to reveal striking new insights into the organization of behavior. Of these systems, Eshkol-Wachman Movement Notation appears exceptionally powerful for extracting invariant features of behavior. We suggest that the adoption of such methods will lead to behavioral taxonomies that are both ecologically and neurologically valid.
\end{abstract}

Until recently, psychology was a philosophical discipline concerned with the nature of mind. During the latter part of the 19th century, it emerged as a scientific discipline. The spirit of the times dictated that mind, like all phenomena, should be regulated by identifiable, regular laws similar to those of Newtonian physics. Mind, however, was not amenable to experimentation because it was not directly observable. In order to found a "science" of psychology, it was necessary to shift the focus of psychology from the mind to overt behavior. As J. B. Watson, the most articulate advocate of a science of behavior, proclaimed, the key to unlocking general psychological laws was the systematic observation and measurement of behavior. Initially, this approach seemed to be a simple one. Behavior appeared easy to observe and measure, and the task of creating a set of general psychological laws did not look insurmountable. In addition, given reasonably general laws of behavior, it seemed that anchoring them to the physiological substrate would be straightforward. An understanding of the organization of the physiology could, in turn, provide predictive explanations of behavior and useful tools for the clinic. The

The preparation of this manuscript was supported by an NSERC University Research Fellowship (No. U0262) awarded to the first author. We are grateful to Tom Calvert, Don Wilkie, Bob Bolles, Sergio Pellis, Sally During, Greg Moran, John Fentress, and Ilan Golani for discussing these ideas with us. With the exception of the first author, the order of authorship is alphabetical. Requests for reprints should be sent to W. J. Jacobs, Department of Psychology, 4401 University Road, University of Lethbridge, Lethbridge, AB T1K 3M4, Canada. apparent power of behaviorism was virtually unlimited. Thus Watson went so far as to claim,

Give me a dozen healthy infants, well-formed, and my own specified world to bring them up in and I'll guarantee to take any one at random and train him to become any type of specialist I might select-a doctor, lawyer, artist, merchant-chief and, yes, even into beggar-man and thief, regardless of his talents, penchants, tendencies, abilities, vocations and race of his ancestors. (Watson, 1928, p. 10)

The promise of behaviorism remains unfulfilled. Compared with other sciences, the progress of the behaviorally based sciences has been painfully slow. Advances similar to those in medicine, physics, or molecular biology seldom occur. Sixty years of concentrated research have failed to provide generally accepted laws of behavior; nor do we understand the physiological mechanisms that organize and produce behavior.

Why has behaviorism failed to fulfill the promise so evident at its inception? We argue that this failure is due primarily to the use of misguided descriptions of behavior. By classifying as similar all behaviors that result in a specific environmental outcome, behaviorism has belied its own name and abandoned the study of behavior itself (Kolb, Jacobs, \& Petrie, 1987; Pfaus et al., 1987). We also argue that researchers using more naturalistic methods of observation, whether intellectual descendants of ethology or of other hybrid disciplines, have failed equally. However appealing, their use of intuitive and informal classes of behavior similarly ignores behavior itself. In its place, they rely on little-understood processes 
of psychological categorization, the unavoidable biases of human perception, and the inadequacies of natural language.

If behaviorism was stillborn in the early part of this century, and naturalistic observation has been inevitably hindered by anthropomorphic bias and inference, it is hardly surprising that the mechanistic models these approaches have generated neither reflect the organization of behavior as it occurs in the natural world nor relate to behavior as it is organized neurophysiologically. We suggest that the inadequacy of traditional approaches to the study of behavior can be overcome if the behavioral sciences adopt an explicit, formal framework for the description of behavior.

\section{TAXONOMIES OF BEHAVIOR}

Taxonomies are not neutral hatracks for the pristine facts of nature. They are theories that create and reflect the deep structure of science and human culture. A taxonomy is not a ploy for convenient arrangement, but a hypothetical statement about the nature of things. (S. J. Gould, 1985, p. 505)

If we are to describe behavior, we must break the behavioral stream into conceptually discrete units and classify them into recognizable behavioral types. Each behavioral type serves as an element of the behavioral taxonomy out of which theory is constructed. However, because no two instances of a behavioral type will be identical, classification depends upon abstracting characteristics common to each type and ignoring those characteristics assumed to be due to momentary variation. In order to classify behavior, we define a "core of invariance" that is recognizable in each class (MacCorquodale \& Meehl, 1954).

For the most part, behavioral scientists choose descriptions of behavior expressed in natural language. Any descriptive language, however, constrains the way in which we can describe and therefore discuss our perceptions. A specific language will allow us to describe a behavioral stream in different ways, but it will also prevent us from describing behavior in other ways. At the simplest level, the act of naming limits the descriptive power of a language. In effect, the choice of a language is the same as the choice of a taxonomy in that it involves classification that makes explicit certain distinctions and hides certain others. In choosing a natural or technical language with which to describe behavior, we are, in effect, implicitly choosing a taxonomy. Because it is implicit in the language, this taxonomy can be changed only by describing the behavior in a new language.

The choice of a particular language, or of an explicit taxonomy, carries with it a second, often ignored, characteristic. When we define a set of behavioral types, the allowable relationships among the types have been brought into existence by default. Therefore, a theory based upon any taxonomic system is fixed in its form, its simplicity, and its power by the way in which behavioral types are brought into existence. If we change the criteria by which behavioral types are established, then a new taxonomy has been created, and new theoretical relationships are implied. This is true whether the change is brought about by altering our explicit definitions through discussion or by changing the language with which we describe behavior. Theories that are derived from different behavioral taxonomies necessarily describe relationships that are unique to their own taxonomies, even though each taxonomy may describe the same behavioral stream.

This point cannot be lightly dismissed. The form, power, and elegance of our theories depend both upon the criteria used to form our behavioral taxonomies and upon the choice of a descriptive language. The taxonomies permitted in the language determine the possible forms that theory can take. More bluntly, the way that we describe and classify events in the natural world determines the theoretical description that can be derived from it (Fentress, 1984; Golani, 1976; Spencer-Brown, 1979; Whitehead, 1929).

This observation leads us to consider the way that we create and recognize the types that make up behavioral taxonomies. The process can be illustrated in the following way. When training undergraduate students in the art of experimental psychology, it is often necessary to provide direct demonstrations of some of the problems involved in the investigation of behavior. One technique we have used requires the students to develop their own behavioral taxonomies. We show the students films of male wolves interacting in a naturalistic setting, and then ask them to create a behavioral taxonomy that they believe adequately captures the ongoing behavioral stream observed in the wolves. It always takes heated and prolonged debate to obtain a set of behavioral types agreeable to all. The students are then provided with new films and are trained to identify each type and to count the number of times that they occur in a given behavioral sequence. Finally, another new film is shown and time-sampling techniques are used to obtain a description of the behavior contained in the sequence.

Several striking facts emerge from this technique. First is the extraordinary variability in the way that students categorize behavior. Second is the tenacity with which the creator of a type will cling to it once it is brought into existence. Third is the length of time required to train each student in the classification system that they themselves have created. Fourth is the fact that no two groups of students have created the same system to describe behavior, even though the same films have been used year after year. Finally, even though the students spend literally hours training themselves and others to recognize their behavioral types, the interobserver agreement is typically poor.

Although it is not obvious at first glance, these problems appear to stem from a single source. Our students describe behavior in terms of the results of actions, or acts, rather than in terms of the movements that constitute these acts. They fail to recognize the difference between behavioral types and the individual units, or tokens, that constitute 
them. ${ }^{1}$ It is difficult to see that behavioral types such as running, chewing, biting, or crouching can be represented by a variety of behavioral tokens. It is even more difficult to see that behavioral types are not real events or things, but, rather, that each type is an abstraction, a collection of tokens constituting a category of behavior. Unfortunately, because the tokens that make up each type have no names, our students are forced to provide such a classification informally. They point at specific examples of behavior and assign each of them a type name.

We believe that the majority of scientists trying to study behavior have precisely the same difficulty as our students. It appears obvious that wolves bite one another, walk around, crouch, look up, and so forth. To students and researchers alike, these types are real, concrete examples of behavior. Consequently, the tokens that constitute them are never studied.

The relationship between type and token is illustrated in Figure 1. The bottom line, the universe of movement, is an abstraction that defines the set of all possible movements for a given species. Two things should be noted about this set. First, the species, indeed the specific animal, is central to the definition of this universe because anatomy determines which movements are possible for a particular animal. Second, although movement unfolds in time, there is no temporal dimension in Figure 1. All possible durations of all possible movements define the universe of movement.

The second line, the tokens of movement, also represents a set of abstract concepts. These tokens comprise all of the potential movements of the body as expressed in a particular language. As a subset of the universe of movement, this level contains peculiarities and blind spots specific to the rules of transcription within the descriptive language that is used; the choice of a language always results in the loss of information. For example, a language that is able to describe only the major limb movements of an animal will be blind to finger manipulations or facial expressions.

At the next level, tokens are combined into the classes that we refer to as behavioral types. It is at this level that most observers intuitively describe behavior. The processes used to group various tokens into types are poorly understood, but whatever the method, the observer

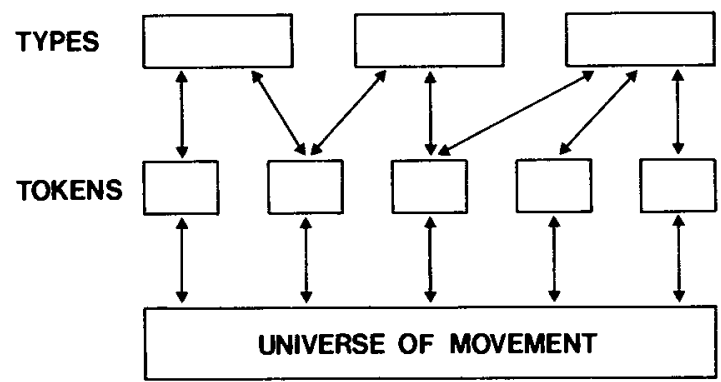

Figure 1. The elements of a behavioral taxonomy: types and tokens. is typically unaware of it. The tokens used to generate behavioral types are not represented in natural language. Only the behavioral types themselves are expressed in words or symbols. Obviously, the tokens that an individual is able to recognize largely determine the content of the behavioral types created by that observer. In addition, even when the names of the types used by each student are the same (e.g., approach, threat, submit), the tokens encompassed by each may differ, in some cases dramatically.

The distinction between type and token leads to a serious concern. Meaningful comparisons may be made among empirical or theoretical constructs only when observers use behavioral types with identical contents. If the contents of identically named types differ among observers, then the relationships among the types must also differ. Consequently, we warn our students to take great care when they use theory generated from a particular taxonomy. Such theory may be limited not so much to the sample of behavior from which it was derived, but to the specific observer who generated the data. These concerns are even more crucial when we try to relate behavior to the nervous system. If the behavioral taxonomy is based on inappropriate criteria, then there can be little hope of finding a neurological basis for the nonexistent "behaviors"' (Fentress, 1984; Gray, 1982).

\section{THE CLASSIFICATION OF BEHAVIOR}

Although we have become more aware that unconscious bias is often hard to avoid, the goal of objectivity remains the foundation on which the success of science rests. No less than in Galileo's day, the deliberate introduction of ideological preconceptions into the scientific process undermines its integrity. (Davis, 1984, p. 294)

If we accept that the way in which we describe and classify events in the behavioral world will determine the behavioral and neurological models that can be derived from it, then the techniques used to describe and classify events are of crucial importance. It may be worthwhile to consider the various ways in which we extract units from the behavioral stream, and then to consider such techniques in light of what we have learned by observing our students.

Although a multitude of methods are used to classify behavior, the most popular is functional classification: Behavior is classified by its consequences. Such classification appears to be both objective and convenient; when a particular goal is accomplished, a behavioral type is said to have occurred. This way of describing behavior says nothing about the movement or action that achieved the goal, but only that the goal has been reached (Hinde, 1982; Lashley, 1952).

The functional criterion has powerful intuitive appeal. Indeed,

One of the most prominent features of the behavior of animals is that it is goal directed. Animals seek food or water, move to a shady place, or explore a novel feature of the environment; man turns up the thermostat when it is cold, 
works overtime in order to buy a new car, or gets up early on Sunday morning to play golf. (Mogenson \& Phillips, 1976, p. 190)

This statement seems to be irrefutable. Moreover, powerful arguments can be offered as a rationale for the use of functionally defined behavioral types. First, such a description refers to all possible behaviors that could lead to a specific outcome. Thus we have a descriptive shorthand that allows highly variable instances of organized movement to be grouped as general instances of goaldirected behavior. Second, humans can recognize behaviors as analogous to one another even if they differ in form (Lorenz, 1974). Third, behaviors that are identical in form may not be homologous (Lorenz, 1974). For example, the kiss of a father, a lover, or a Judas Iscariot must be classified differently, even if the movements that constitute the kiss are identical. Fourth, functional descriptions may bring attention to environmental consequences of the behavior that would have remained unnoticed if it were merely described physically (Hinde, 1959, 1970). Finally, to the extent that a goal is physically defined, the environmental consequences can serve to designate the beginning and the end of a given behavioral sequence.

\section{Radical Behaviorism}

The most influential behavioral taxonomy based upon the functional classification of behavior has been Skinner's (1938) concept of the operant. Skinner analyzed behavior in terms of its impact on the environment. This strategy is similar to the one used in naturalistic observations in that behavior is classified according to outcome classes (e.g., feeding, fighting, mating). However, Skinner's formal taxonomy is more elegant; it greatly simplifies the classification problem. Rather than a multitude of goals, a behavior has only one. If it manipulates the environment, then it is an operant; if it does not, then it is something else. The movements that constitute the behavior, or the species that produce it, play no important role in this kind of analysis.

It is important to note that the operant, defined in this way, is neither a temporally nor a spatially extended biological event. Rather, it is a type of behavior formally and powerfully defined by its consequences. Thus, the study of the operant is not the study of behavior or action; rather, it is the study of the impact of behavior on the environment-the study of work. Defined in this way, the operant captures neither the spatial nor the temporal organization of the behavior of the species; instead, it captures the interaction of behavior with the environment. Skinner clearly delineated the nature of the operant in just this way:

The unit of a predictive science is ... not a response but a class of responses. The word operant will be used to describe that class. The term emphasizes the fact that the behavior operates upon the environment to generate consequences. The consequences define the properties with respect to which the responses are called similar. (Skinner, 1953, pp. 64-65)

In the laboratory, the definition of the operant is further refined. There, what unites all operants is a common impact on the environment: a microswitch is closed. Those studying the operant demonstrate impressive control of behavior as classified by the operation of microswitches. Behaviorists have worked out operant rules that are powerful predictors of behavior in the Skinner box. Unfortunately, as their application has been carried forward, the rules have been treated as if they applied to biological events: The rules found through the "experimental analysis of behavior" have come to be applied to behavior in general rather than to the operant. As a result, highly confusing data have accumulated.

For example, Breland and Breland $(1961,1966)$ found that several species exhibit behaviors, typically classified as operants, that are not responsive to operant contingencies. ${ }^{2}$ In a comprehensive review, Shettleworth (1972) pointed out more explicitly that many species exhibit behaviors, classified as operants, that do not follow operant rules. She urged that naturalistic observation be used to generate a catalogue of behavior that allows us to recognize behavior in its various forms (for reviews, see Domjan, 1984; Domjan \& Galef, 1983; Shettleworth, 1972, 1983a).

A parallel development occurred in the applied setting. Clinicians found that behavior-modification programs worked well under some circumstances but not under others. Schedules of reinforcement were found to control only certain forms of human "behavior," and only under certain conditions. Although certain behaviors could often be controlled, there were other behavioral types that did not appear to follow operant rules. These behaviors existed without performing work. They were actions, not operants.

Similar problems emerged in the behavioral sciences and behaviorally based neurosciences (see Bolles, 1967). Here, as in the operant tradition, the classification of behavior was laboratory based (e.g., barpresses, errors in a maze, grams of food consumed, and reaction times). Because laboratory instruments were used to classify behavior into types without specific recognition of individual tokens, behavioral tokens were not formally defined. As a result, many behavioral theories were designed to account for types of behavior as defined by laboratory instruments. This forced neurobiological investigators to treat the identified behavioral types as the phenomena for which they were to provide mechanistic accounts. Unfortunately, evidence for the validity of these behavioral types was not found in the brain. Moreover, the tokens that constituted the behavioral types were invisible to such theory; the organization of behavior as it unfolded within a spatial and temporal context was lost both in the data base and in the theoretical accounts. In the end, the use of laboratory-based classification of behavior yielded a 
meager taxonomy that, some argued, was neither ecologically nor neurologically valid (cf. Johnston, 1981; Uttal, 1978).

\section{Ethological Perspectives}

The observations outlined above indicate that a fundamental problem exists in the data base of the behavioral sciences (Johnston, 1981). In the laboratory, types of behavior are often defined with an eye toward ease of measurement rather than toward their ability to represent behavior as it unfolds in other contexts. As a result, theory constructed from arbitrary laboratory-based types may generalize only to a situation similar to that found in the laboratory (see Gottlieb, 1976). This realization led some to suggest that the behavioral types used in the laboratory must be representative of "real" behavior as it occurs in the life of the organism. Naturalistic observation became a key to the research process.

The function of naturalistic observation is to reveal biologically important types of behavior, the relationships among those types, and the circumstances under which they occur. The elegance of this approach resides in the fact that an organism, responding in its home environment, provides us with behavioral concepts common to both the laboratory and the "natural" world (e.g., Alley \& Shaw, 1981; Cole, Hood, \& McDermott, 1982; Domjan, 1984; Eibl-Eibesfeldt, 1979; Garcia, Rusiniak, \& Brett, 1977; Hinde, 1970; Hoyle, 1984; Johnston, 1981; Rozin \& Kalat, 1971; Shettleworth, 1972).

This view is based upon the idea that a properly constructed behavioral taxonomy consists of types that can be studied either in the laboratory or in the field. Laboratory-based behavioral data can be used to predict, and perhaps control, behavior as it unfolds in more complex settings, and the field-based data can be used to guide and validate laboratory investigations. Behavioral types could be obtained using strategies far more rich and yet less formal than Skinner's. This strategy is based upon the model offered by the European ethologists (e.g., Lorenz, 1950; Tinbergen, 1951).

Ethologists spend time, often years, observing the raw unclassified behavioral stream, simply watching behavior in a variety of situations. Eventually, intuitive breaks in the behavioral stream are found. These behavioral breaks exhibit characteristics of two kinds: Highly stereotyped motor patterns, or a stereotyped impact on the environment. A behavioral unit is defined by its motor pattern or by its environmental consequence. Thus, the "gaping" response of young nestling birds or the egg-rolling pattern of a nesting greylag goose (Lorenz \& Tinbergen, 1938/1970; Tinbergen, 1951) was recognized by its movements, whereas the hoarding activity of a bird (Shettleworth, 1983b), the homing behavior of a digger wasp (Tinbergen \& Kruyt, 1938), or the burying behavior of a rat (Pinel \& Treit, 1978) was recognized by its consequence.

Tinbergen expressed the following opinion:

Because it is our task to analyze behaviour as co-ordinated muscle activity, the ultimate aim of our description must be an accurate picture of the patterns of muscle action. Except in some especially simple cases, this has never been done, probably because most workers are only dimly aware of the necessity. (Tinbergen, 1951, p. 7)

In contrast, others argued that the description of muscle activity or movement is "not only impracticable, but also unnecessarily refined and cumbersome" (Hinde, 1970 , p. 569), and that such a behavioral taxonomy "is unsuitable in some cases because of the complexity of the data it provides and in others because the data cannot be subdivided into classes with objective validity" (p. 13).

Each of these strategies has its advantages and its disadvantages. When describing behavior by its motor patterns, ethology stays close to behavior as it occurs, but is confronted with an overwhelming amount of detail. When describing behavior by its consequences, the impact of movement upon objects in the environment is captured, but the form of the movement is lost. In practice, these two strategies were often blended or used interchangeably.

Once behavior is classified, data collection begins. Ethologists spend time, again often on the order of years or decades, collecting and analyzing data. During this time, categorization schemes are refined or altered to accommodate current hypotheses and newly noticed behavioral characteristics. With increasing knowledge, the categorization schemes can increase in sophistication and technique. With an increased understanding of behavior, the ethologist can use several strategies to categorize behavior. For example, various behaviors can be categorized on the grounds that they share common causal factors, they are acquired in the same way, they lead to the same consequences, or they are evolutionarily related (see, e.g., Dewsbury, 1978; Hinde, 1959, 1970, 1982).

The advantages of this multilevel strategy (e.g., Hinde, 1970) made it the method of choice in the naturalistic study of behavior. However, the complexity involved in recognizing and counting behaviors categorized in this way precludes the use of Skinner's technological approach to data collection. The recognition of behavioral types, and the counting of them, can be done only by humans, not by mechanical instruments. The human observer, then, has to be trained to record data as reliably as any other instrument. In effect, the observer has to be trained to behave like a microswitch in a Skinner box. The classification strategies, the conclusions, and, as we have seen above, the theories based upon this kind of datum depend crucially upon the ability to calibrate the human observer: Ethology depends crucially upon the assumption that data collected in one place and time are comparable to data collected at another place and at a different time.

\section{Observing Observers}

Students of behavior assume that observation allows an objective assessment of the important characteristics of ongoing behavior. Ironically, it was the observation of our students that taught us to suspect the veracity of this assumption. Our students seemed to be unable to classify 
behavior objectively or to record consistently the occurrence of behavioral types that they themselves had defined. In order to support our suspicion that these are universal characteristics of the human observer, we found it instructive to turn from studies of animal behavior to studies of observers themselves.

After behavioral types have been defined, observations are initially carried out by those who created the taxonomy. Later, the taxonomist may train students, who may in turn train others. Unfortunately, several studies have shown that this commonly accepted approach profoundly degrades the quality of data taken from the field. For example, Taplin and Reid (1973) and Wildman, Erickson, and Kent (1975) showed that observers trained to use identical observational criteria, but by different instructors, recorded markedly different data. Apparently, instructors train observers idiosyncratically, even when guided by explicit observational criteria. Furthermore, the nature of observational data is affected not only by the trainer, but also by the training method. Observers trained through direct observation of behavior will later record field data differently than will observers trained through the use of videotapes (Kent, O'Leary, Dietz, \& Diament, 1979).

More importantly, it appears that human observers do not record behavioral data consistently or objectively. For example, the behavioral records produced by the observer tend to become increasingly stereotyped as the observer gains experience with the members of a population under observation. This effect, known as ipsative drift, indicates that the sensitivity of the recording device changes as a function of experience, becoming less sensitive to variations in behavior over time (Redfield \& Paul, 1976). Moreover, low variability in the observational material can quickly render the observer insensitive to variations in the ongoing behavior (Mash \& Makohoniuk, 1975; Mash \& McElsee, 1974).

The criteria that observers use to classify behavior are also influenced by the circumstances under which the recording takes place. For example, when observers are told they are undergoing reliability checks, interobserver agreement is typically greater than $70 \%$, but when the same observers are checked without their knowledge, agreement drops precipitously (Kent, Kanowitz, O'Leary, \& Cheiken, 1977; Reid, 1970; Taplin \& Reid, 1973). In addition, if observers are aware of the outcome expected by the principal investigator, they change the criteria used to record behavior. This effect is even more pronounced if they are given feedback by the principal investigator regarding the quality of the observational record (Kent, O'Leary, Diament, \& Dietz, 1974; Shuller \& McNamara, 1976). Moreover, observations may be influenced simply by the affective qualities of the names given to various behavioral types. Observers record the occurrence of a behavioral type more often if it is given an affectively negative label than if it is given a neutral or positive label (Farkas \& Tharp, 1980).
Several other factors influence the criteria used by the human observer during data collection. For example, increasing the complexity of a classification scheme, or increasing the level of inference required to type behavior, decreases the accuracy of behavioral recordings (Jones, Reid, \& Patterson, 1974; Longabaugh, 1980; Mash \& McElwee, 1974; Taplin \& Reid, 1973). Furthermore, observer performance fluctuates as a function of fatigue, forgetting, and motivation, an effect known as observer decay (Campbell \& Stanley, 1966).

Finally, the criteria used by human observers to record behavioral data are unstable across time. For example, observers "drift" relative to one another over observational sessions. If observers do not have the opportunity to collaborate (as in most studies done in separate laboratories), the interobserver agreement systematically decreases over time. If they collaborate, the agreement within collaborative pairs remains at a high level, but the pairs of collaborators drift relative to one another. This effect, known as consensual observer drift, is often dramatic. Initial agreement among all observers may be in the $60 \%-80 \%$ range at the beginning of a study, remain in that range for all collaborative pairs throughout the course of the study, and yet lie within the $20 \%-40 \%$ range among noncollaborators at the end of the study (DeMaster, Reid, \& Twentyman, 1977; Kent et al., 1974; Romanczyk, Kent, Diament, \& O'Leary, 1973; Wildman et al., 1975).

There are those who will argue that distortions in observationally based data are distributed evenly throughout behavioral records and across laboratories. We claim that this assumption is not justified. Many of these biases are systematic and develop over time; others are not stable across time. There is no known way to avoid the errors, or to distribute them evenly throughout the observational records. No known techniques allow us to measure and remove error from our observational records. These studies have a single, devastating implication. The typical observational study relies upon an instrument whose sensitivity, range, and accuracy fluctuates over time in an unpredictable manner.

This litany of findings suggests that those interested in the observation of behavior are faced with serious problems. If different investigators train observers, then, although the behavioral taxonomies used by different laboratories may be composed of nominally identical types, the tokens that constitute each type may differ. Moreover, if the same investigator changes training methods, then the data subsequently collected will not be comparable to those collected earlier. In addition, data collected by an experienced observer may not be comparable to data collected by an inexperienced observer, or even to data previously collected by the same observer (for reviews, see Boice, 1983; Harris \& Lahey, 1982; Kent \& Foster, 1977; Longabaugh, 1980). With the problems of observer drift, ipsative drift, observer decay, and the other factors outlined here, empirical and 
theoretical comparisons among laboratories observing nominally identical materials may be meaningless.

\section{Biases in Observation}

Modern Ethology's greatest opportunity is also its most difficult to realize: we must use the ethological perspective to extend our knowledge of Homo Sapiens. Our own anthropomorphic biases give us a curiously foreshortened perspective which makes it difficult not to consider the species as a special creation, somehow exempt from the evolutionary continuum.... We are often, as von Frisch taught us, blind to our own blindness. We cannot readily see what evolution did not design us to see, or perhaps to think or imagine beyond the built in limits of the system. (Gould, 1982, p. 489)

The data surveyed in the previous sections give us reason to assert that the observation of humans and other animals is fraught with difficulty. Yet some might argue that our current observational techniques, no matter how poor the resolution, will ultimately direct us toward viable behavioral taxonomies.

We are not so optimistic. When beginning an observational study it is all too easy to impose preconceived behavioral categories on the material being studied. Introspectively derived concepts such as fear, anxiety, hunger, thirst, and play are intuitively reasonable, but the behavior of other species, or even our own, may not be organized around such inferred states.

The human observer suffers from another fundamental flaw, the flaw of seeing behaviors that conform to the pattern of adult human experience. Researchers studying human development have long recognized the pervasive influence of intuitive categorization. Adults invariably view infant behaviors as if they were nascent adult behaviors, as if they were performed in order to accomplish an end, or as if they were directed toward a goal easily recognized by adults (Hopkins, 1983; Mackay, 1972; Mitchell, 1911; N. Oppenheim, 1898; R. W. Oppenheim, 1980). This implies that the ways in which the behavior of any species is categorized are inevitably influenced by anthropomorphic biases. In the analysis of behavior, we bias our observations through the use of classification schemes that reflect the way that we categorize our own behavior, and further distort our observations by inconsistently recording the occurrence of such behavioral types. As a result, we can in no way be confident that observations recorded using such taxonomies and methodologies have any validity as a description of the behavior of any species. ${ }^{3}$ This produces an additional dilemma for the neuroscientist who may attempt to find neural correlates for behavioral types that exist only within a subjectively derived taxonomy.

The acceptance of intuitively based methods of behavioral classification leads to other plausible, but possibly incorrect, concepts. For example, concepts that are fundamental to our thinking, such as the goal directedness of behavior (Tolman, 1932), the functional equivalence of responding (Lashley, 1952), and the division of behavior into consummatory and preparatory classes (Konorski, 1967), depend upon the a priori acceptance of introspectively derived, but possibly incorrect, categories of behavior.

\section{FORMAL METHODS OF BEHAVIORAL OBSERVATION}

When behavior is being observed in the laboratory or a naturalistic setting, the inferential nature of the data is not explicit: We believe our data to be objective and real. It would be to our advantage to develop a method to formalize the way that behavioral tokens are defined and transcribed from the behavioral stream. With formal specification, the contents of a type would be known and subject to public scrutiny. Our notions concerning the classification and organization of behavior would then be vulnerable to empirical disconfirmation.

To this end, we recognize that behavioral types are complex movements, made up of multiple components, and that each of these components may be involved in many types of behavior (Satinoff, 1982). If behavior could be described using formal records of movement, the tokens that are constructed could be accurately communicated to others. It would then be possible to conduct a meaningful debate concerning the way in which the behavioral types are created. ${ }^{4}$

There is a substantial literature that supports this position. Several lines of investigation indicate that, by using refined and objective analyses of movement, it is possible to circumvent many of the problems we have outlined.

\section{Facial Expressions}

Ekman and Friesen have successfully characterized human facial expression by creating a formal notational system (Ekman \& Friesen, 1978a, 1978b, 1978c). The Facial Action Coding System (FACS) is a system that allows the formal description of the patterns of muscle action in the human face.

Prior to the development of FACS there was no adequate way to describe the behavioral tokens of facial movement. As a result, researchers relied on intuitively defined types of behavior. With FACS, the tokens of facial expression are derived from anatomy and are recorded in terms of specific sets of muscle contractions. It is then possible to create explicitly defined higher level categories such as "smile" or "grimace." For example, theorists can formally define what they mean by "an expression of disgust" and be confident that their definition will be unambiguously communicated to colleagues in other laboratories.

The data gathered thus far are impressive. For example, some have argued that facial expressions are speciestypical, whereas others have held that facial expressions are determined by culture (Birdwhistle, 1952; Chapple, 1940, 1949, 1970a, 1970b; Darwin, 1872). FACS has been instrumental in demonstrating that certain expressions are universal in both literate and preliterate cultures 
(Eibl-Eibesfeldt, 1972; Ekman, 1972, 1973; Ekman \& Friesen, 1971), and in delineating precisely which aspects of facial expressions are culturally determined (Ekman \& Friesen, 1969, 1975). FACS has also been used in clinical assessment and treatment, providing insights in psychotherapy (Ekman \& Friesen, 1968, 1969) and pain research (Craig \& Patrick, 1985; Craig \& Prkachin, 1983; LeResche \& Dworkin, 1984).

\section{Taste Hedonics}

A similar type of formal descriptive system has developed within the motivational literature. Grill and his associates (e.g., Grill \& Norgren, 1978) have taken a novel approach to the study of feeding. They have used detailed analyses of stereotyped response patterns to infer the hedonic reactions of rats to various sorts of taste stimuli. The infusion of a sweet solution into the mouth of a hungry rat elicits "appetitive" protrusions of the tongue and rhythmic movements of the mouth. In contrast, infusions of an unpalatable quinine solution evoke a "rejection" sequence consisting of gaping, chin rubbing, head shaking, face washing, forelimb flailing, and paw rubbing.

Using these identified response patterns, it has been possible to enrich the analysis of hedonic responses. Young (1966) asserted that there was a one-dimensional hedonic continuum ranging from like to dislike, whereas Berridge and Grill (1983) found that rats will respond to some solutions (e.g., ammonium chloride) with a combination of appetitive and rejection reactions. These data indicate that there are at least two separate hedonic dimensions for taste. Similarly, it has been found that rats will avoid sucrose solutions that have been paired with either toxicosis or electric footshock, but only in the first case will the rats react to the taste of the sucrose as if it were unpalatable (Pelchat, Grill, Rozin, \& Jacobs, 1983). In the case of shock, rats briefly respond to the infusion of the sucrose as if it were palatable, then jump away and cower at the back of the cage. It appears that the rats like the taste but avoid consuming the food, much as humans will avoid eating a food that gives them hives, although the taste remains pleasant (Pelchat \& Rozin, 1982).

\section{Clinical Applications}

In clinical populations, it is widely recognized that different disorders are characterized by stereotyped patterns of "nonverbal behaviors" or movements (e.g., Hill, 1974), ${ }^{5}$ and there are several lines of evidence which indicate that careful examination of movement may provide important insights into mental disorders. These include suggestions that valid diagnosis requires an examination of behavior in its entirety (Pansa-Henderson, de L'Horne, \& Jones, 1982), that nonverbal behavior is closely related to the pathophysiological substrate (World Health Organization, 1983), and that it is more difficult to consciously alter nonverbal behavior than one's words (Helmchen \& Renfordt, 1981).

Several research groups have applied techniques for recording and measuring characteristics of movement to the study of clinical populations. For example, Condon and his associates (e.g., Condon, 1977, 1979; Condon \& Brosin, 1969; Condon \& Ogston, 1966, 1967) have studied the interaction of speech and nonverbal behavior in the communication of messages. They noted that listeners can be very clear about what a person said and meant in the rapid flow of conversation, without being able to tell precisely how they knew (Condon \& Ogston, 1967).

By analyzing a film and its soundtrack frame by frame, Condon and Ogston (1967) notated changes in the direction of movement of all body parts and found that this allowed them to define "process units." These behavioral units begin whenever at least two body parts change direction simultaneously, and end when the movements of these body parts are no longer coordinated.

Condon and Ogston $(1966,1967)$ found that process units coincided in time with linguistic units to a remarkable degree. In fact, process units almost always shared beginnings and endings with linguistic units in all nonpathological subjects. The authors called this coincidence of movements and speech "self-synchrony." It was especially important for their interest in communication to discover that the body movements of a listener are also coordinated with the speech and body movements of a speaker (Condon, 1977, 1979; Condon \& Ogston, 1966, 1967). This "interactional synchrony" appeared to play a role in the perception of meaning. This synchrony has been found in infants as soon as $\mathbf{2 0}$ min after birth (Condon \& Sander, 1974). Condon (1979) suggested that this synchrony may facilitate the discrimination of different phonetic units by infants: The structure of the speech may be revealed to them by the structure of their own body movements.

This self-synchrony breaks down in certain forms of pathology. For example, Condon and Brosin (1969) found that an aphasic subject showed a delay in voice onset of approximately $42 \mathrm{msec}$, relative to the onset of a motoric process unit. In a stutterer, body motion began prior to the onset of speech, and certain hand movements were out of phase with those of the head. A depressive patient exhibited dyssynchrony between certain fingers and the rest of the body, and, during a stressful utterance, between the head and the eyes. Many schizophrenics also displayed dyssynchrony between movement and speech. For example, in a catatonic schizophrenic, movements of the eyes and mouth were out of phase, and in a paranoid schizophrenic, movements of one arm were out of phase with the rest of the body and with speech during a stressful utterance.

Interestingly, autistic children were found to move in synchrony with environmental sounds, but not with speech. Furthermore, autistic children revealed an unusual form of dyssynchrony in which they moved in synchrony with a sound as it occurred, but failed to habituate to repeated presentations of the same sound. This pattern culminated in violent jerks that occurred at predictable intervals (Condon, 1979). 
A second technique for analyzing movement during clincial interviews was developed by Frey and his colleagues (Fisch, Frey, \& Hisbrunner, 1983) to examine the movements of depressed subjects over the course of recovery. In their system, positions of body parts were coded in various dimensions for every frame of a videotape. As expected, Fisch et al. (1983) found that depressed clients exhibited reduced motor activity, monotony and poverty of movement, and difficulty in initiating movement, symptoms long associated with depression. What was unique about this analysis was that these symptoms were formally and objectively quantified. Fisch et al. found that as patients recovered from depression (according to psychiatric ratings), they displayed increased motor activity, more complex patterns of movement, and more rapid initiation and termination of movement. Although the changes in the complexity of movement with recovery were small, too small to be readily discerned without the aid of the formal measurement system, they were so systematic that it was possible to use this measure to quantify various stages of recovery.

\section{Summary}

The research described in this section covers topics ranging from taste hedonics in rats to psychiatric disorders in humans. Nevertheless, all research projects are similar in one important respect: Each uses a taxonomy based upon formal description of behavioral tokens in terms of motor responses. That is, the foundation of each taxonomy is a formal set of behavioral tokens with which formal behavioral types can be defined unambiguously.

This approach has several advantages. First, the same behavioral types can be used with confidence at all times, by all investigators, even those working in separate laboratories. Second, theoretical debate based upon the results of such studies may be carried on in a coherent manner. Because each program uses a behavioral taxonomy based upon formally defined tokens of behavior, the resulting behavioral types are not lapidary, but are subject to refutation and falsification.

These considerations are critical to the study of the neurobiological basis of behavior. The use of a formal system permits a fine-grained description of the complex movements that constitute behavior. A precise knowledge of these units is necessary for determining the substrates of coordinated behavior. In turn, an adequate understanding of motor "output" systems may provide a path to the identification of neural systems involved with higher levels of integration. For example, Grill and his colleagues have utilized information gleaned from their analysis of taste reactivity in the study of central mechanisms of taste, ingestion, and taste aversion learning (see Grill \& Berridge, 1985).

There is much to be gained by studying behavior in terms of explicitly defined behavioral types and tokens. At the same time, we do not discount the importance of functional analyses of bchavior; even those who use ex- plicit behavioral taxonomies argue the necessity of functional analyses (e.g., Grill \& Berridge, 1985). However, a functional approach can be assisted only by the clear definition of behavioral types and tokens. We propose that formal and rigorous analyses of behavior must be firmly rooted in formal and explicit descriptions of movement. The following section describes a powerful method of executing such analyses.

\section{THE ESHKOL-WACHMAN MOVEMENT NOTATION SYSTEM}

The Eshkol-Wachman (E-W) Movement Notation System (Eshkol \& Wachman, 1958) was used initially as a choreographical tool to make permanent records of dance sequences in a form that allowed them to be fully reconstructed at a later time. Because it is a movement nota-

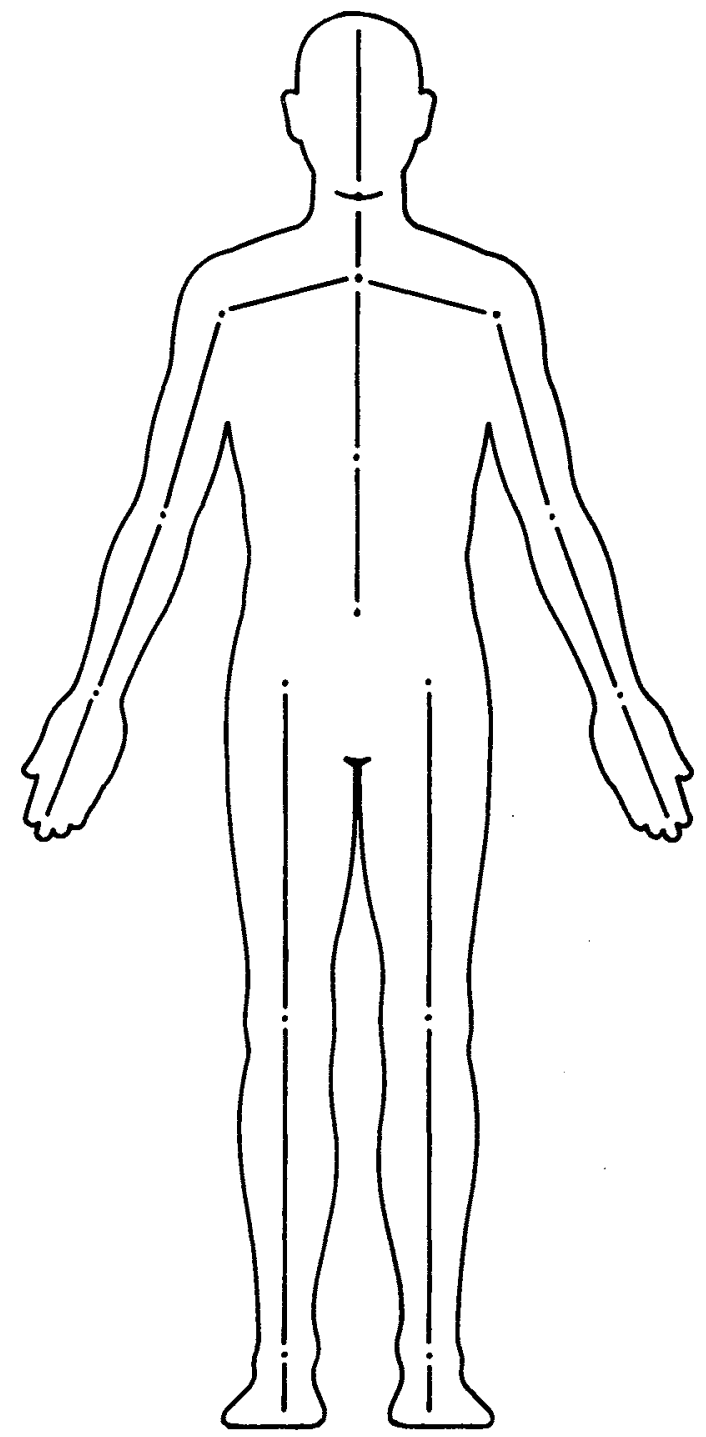

Figure 2. A possible configuration of limb segments in a human. 
tion rather than a dance notation, the E-W system can be used to notate any possible movement independent of a stylistic bias. This makes it ideally suited to the task of providing formal and objective descriptions of behavior. $^{6}$

The E-W system treats the body as a set of limb segments, where a limb segment is defined as any part of the body that lies between two joints or between a joint and an extremity. Figure 2 illustrates a possible configuration of limb segments in a human.

To understand how movements are conceptualized in the E-W system, first imagine a limb moving about a particular joint (see Figure 3). In this particular instance, the proximal joint is referred to as the carrying joint. In the E-W system, the movements of any limb segment are

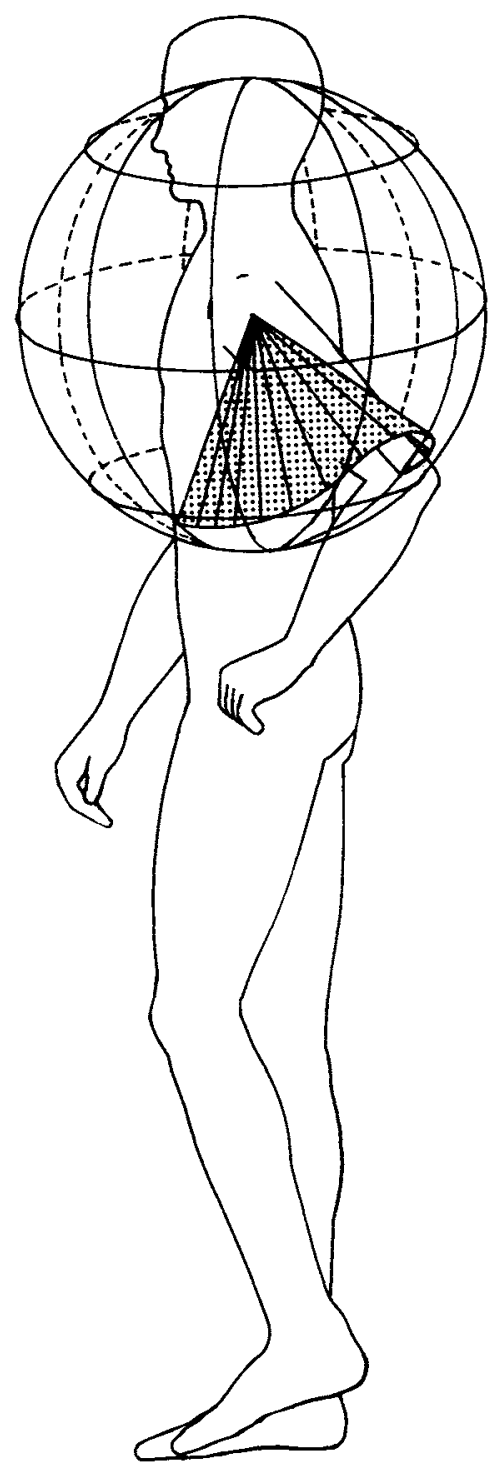

Figure 3. An Eshkol-Wachman sphere centered at a shoulder joint. The path of the elbow joint (the other end of one limb segment) is traced on the surface of the sphere.

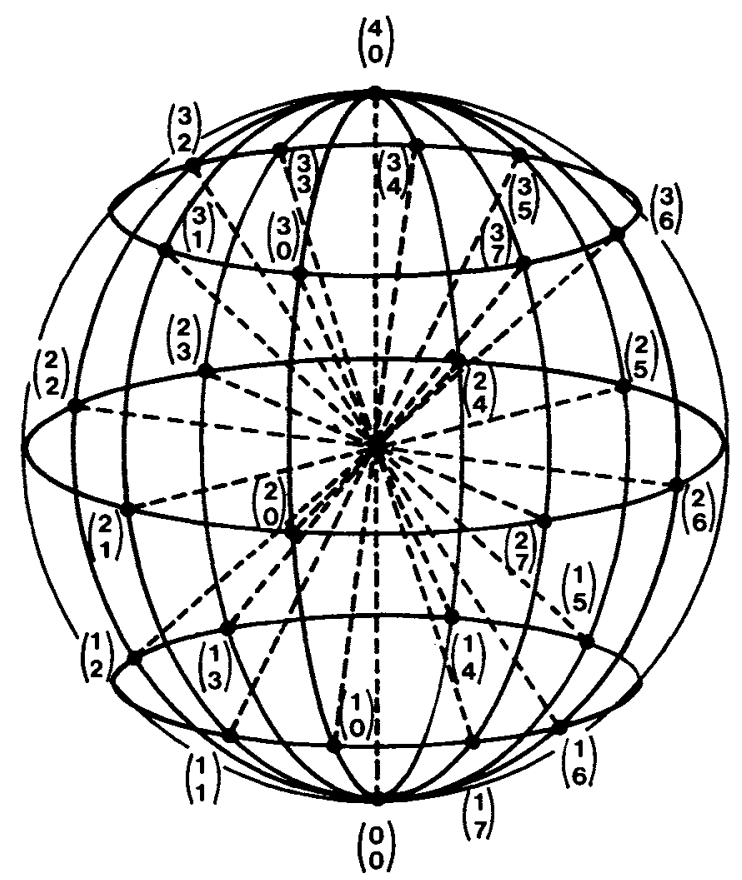

Figure 4. An Eshkol-Wachman sphere with coordinate lines marked at $45^{\circ}$ intervals. Positions on the surface of the sphere are specified by two coordinates that indicate displacement in the vertical (upper number) and horizontal (lower number) planes.

described relative to an imaginary sphere centered at the carrying joint. The other end of the limb segment traces a path on the surface of the sphere (see Figure 3).

The sphere, like a geographer's globe, is marked by coordinates analogous to lines of latitude and longitude (see Figure 4). These lines may be "graduated" to the degree of resolution required by the investigator. Thus, the position of any limb segment may be specified by two coordinates, analogous to the lines of latitude and longitude of the geographer's globe.

The system defines limb movements using variables such as the initial position of the limb; the direction of the movement (clockwise or counterclockwise); and the final position of the limb. One movement is distinguished from the next whenever the value of any of these variables changes. The notation describes a movement by its initial position, its final position, and the trajectory followed between them.

The fundamental elements of the notation are the records of limb position and trajectory (the transition between positions). The movement of any limb can be defined completely in terms of its initial position and subsequent trajectory, with the final position of one movement also serving as the initial position of the next movement. The notation of behavior in terms of trajectories and positions allows the researcher to describe behavior either by the movements involved or by the body positions produced, and to alternate freely between the two perspectives even in the analysis of a single behavioral se- 
quence. As the observer alternately categorizes behavior by movement or by body position, however, the choice of behavioral types is always explicit and objective.

A second key feature of the E-W system arises from the coordinate system used to describe movement. The coordinates can be defined with respect to a sphere centered on the carrying joint of a limb, or a partner involved in the movement, or a fixed feature of the environment. For example, consider a couple waltzing. The movements involved in the dance may be described in terms of the relation between adjacent limb segments of an individual dancer, in terms of the limbs of one dancer relative to the partner's body, or in terms of each dancer's body relative to the orchestra. Although each transcript that is produced when a given behavioral sequence is notated in different frames of reference is formally equivalent, each will reveal a unique perception of the organization of the movements involved in the behavior: one frame will highlight regularities that another frame obscures.

It is clear that the use of the E-W system will permit the researcher complete freedom to choose the approach that is most appropriate for the analysis of a particular behavior. The choice of a particular frame of reference will determine the kind of regularities of movement and positions that become apparent, whereas the choice of an analysis in terms of either positions or movements will determine the kind of theoretical models that emerge. The key is that the description of the behavior will be unbiased. The observer's creativity will be captured in the frames of reference chosen to study the behavior, and reflected in the elegance of the model developed to account for the observed movements. The behavioral description itself will be captured in formal, objective, and permanent records so that other researchers can compare behavioral data directly, explicitly, and meaningfully (Schleidt, Yakalis, Donnelly, \& McGarry, 1984). As a result, theoretical disagreements will be able to focus on the subjectivity involved in the explanation of the behavioral data rather than on the subjectivity involved in their acquisition.

\section{Applications of the E-W System to the Analysis of Behavior}

The strongest advocate of the use of the E-W system for behavioral analyses has been Ilan Golani (e.g., Eisenberg \& Golani, 1976; Golani, 1976; Golani, Bronchti, Moualem, \& Teitelbaum, 1981; Golani, Wolgin, \& Teitelbaum, 1979). In his early work, Golani (1976) made extensive use of the E-W system to describe the social behavior of jackals and Tasmanian devils. This method of behavioral description revealed marked similarities in the movements involved in the social behavior of these animals, an impressive feat considering the evolutionary and anatomical distance between them. By describing behavior in terms of the movements of an individual animal as well as their relation to its partner, the E-W system allowed the abstraction of common features of behavioral organization across species with vastly different anatomical structures.
The utility and elegance of the E-W system for behavioral analyses has been further demonstrated by Moran, Fentress, and Golani (1981), who used it to examine the "ritualized fighting" behavior of wolves. Earlier studies had noted the overwhelming complexity of the social relations involved in this behavior, but had failed to capture and describe this complexity because "the variety and relational nature of the movement of interacting wolves necessitated a conceptual and analytic framework not [yet] available" (Moran et al., 1981, p. 1146). The $E-W$ system, because of its multiple frames of reference, allowed Moran et al. to describe interactions among the wolves more completely. The use of the E-W system in their analysis allowed "behaviour that initially appeared as a sequence of unintelligible gestures ... [to be] understood in terms of straightforward regularities along several dimensions of movement in real and interactional space" (pp. 1162-1163). Through use of the explicit description and formal analysis of the E-W system, what initially had appeared as complex and intricate behavior patterns fell into highly regular, relatively invariant motor processes.

Similar insights have emerged in the work of Pellis (1982), who used the E-W system to analyze the courtship and mating strategies of Cape Barren geese and discovered that pairwise orientation during courtship interactions, as well as the areas upon a partner's body that are pecked, differ markedly from the pairwise orientation and pecking strategies exhibited during an aggressive encounter (e.g., fighting). This analysis also showed that courtship interactions occur throughout the early stages of the female's reproductive cycle, interactions previously viewed as aggressive. Pellis (1981) also used the E-W system to differentiate social play from aggressive interactions in Australian magpies.

Golani and Fentress (1987) used the E-W system to examine the ontogeny of facial grooming in mice. It was obvious to them that the complicated morphological changes characteristic of the development of grooming in mice required them to abandon a simple "compartmentalized" approach (Fentress, 1984). In its place, they used the E-W system to examine patterns of contact between the forepaws and face. In their analysis, Golani and Fentress noted that the developmental sequence begins with a set of many poorly coordinated movements that do not form sequences as distinct as those seen in adult animals. The use of a formal notation system revealed to them how these first attempts at grooming gradually develop into a set of a few simple, stereotyped movements which subsequently evolve into the rich variety of precise movements typical of facial grooming in adult mice (Fentress, 1984; Golani \& Fentress, 1987).

The E-W system has also been an integral part of the approach taken by Golani, Teitelbaum, and their colleagues in a series of comparative studies examining the behavior of infant rats and of brain-damaged or drugged adult rats (Golani et al., 1981; Golani et al., 1979; Szechtman, Ornstein, Hofstein, Teitelbaum, \& Golani, 1980; Szechtman, Ornstein, Teitelbaum, \& Golani, 1985). In 
these studies, a formal description of behavior revealed remarkable behavioral parallels among these three preparations and helped to uncover important underlying principles regarding the functional organization of the nervous system.

Much of this work has focused on the analysis of the behavioral effects of lesions to the lateral hypothalamus (LH). Following damage to the $\mathrm{LH}$, a rat will perform motor responses that are directed toward itself (e.g., grooming, scratching, yawning, sniffing), but not those directed toward the external environment (e.g., orienting, scanning, locomoting, biting and licking external objects) or any "spontaneous" actions. Later in recovery, the rat will respond to external stimuli, and after further recovery will perform spontaneous actions in the context of environmental cues, resulting in apparently normal "'motivated"' behavior (Marshall, Richardson, \& Teitelbaum, 1974; Marshall, Turner, \& Teitelbaum, 1971; Teitelbaum, Schallert, \& Whishaw, 1983).

Teitelbaum and his associates believed that this pattern of recovery from LH damage represented the gradual emergence and reintegration of isolated behavioral subsystems involved in postural support, locomotion, orientation, and scanning. However, because each subsystem recovers separately, at different rates, Teitelbaum and his colleagues found it difficult to study the dynamics of the recovery using ordinary observational methods (Teitelbaum, 1986). To overcome this problem, they began to use the E-W system to analyze the behavior of LHlesioned rats (Golani et al., 1979).

Each LH animal was filmed throughout the recovery process, from total akinesia to relatively normal locomotion. A frame-by-frame analysis using the E-W system revealed a lawful, regular recovery of function in a cephalocaudal (from head to tail) progression within each movement subsystem. This cephalocaudal progression of limb movements is similar to the behavior of a recovered animal when it is placed in an open field and to the exploratory behavior of an intact animal (Golani et al., 1979). Furthermore, a cephalocaudal progression is evident in the ontogeny of exploratory behaviors in infant rats, cats, and badgers. The similarity of these behaviors across species, and in the young or traumatized of a single species, suggests that the expression of behavior in these different contexts shares a common neural substrate.

In a parallel line of research, Szechtman, Golani, and their colleagues (Szechtman et al., 1980; Szechtman et al., 1985) studied the behavior changes caused by the systemic administration of apomorphine, a dopamine receptor agonist, in the rat. In direct contrast to the process of recovery following LH lesions, an apomorphine-treated rat begins a sequence of behavior with excessive locomotion along the forward and vertical dimensions. As these dimensions diminish in amplitude, lateral trajectories increase, transforming forward locomotion into circling, pivoting, and, eventually, small lateral movements of the forequarters. These investigators found that many of the previously reported stereotyped behaviors elicited by apomorphine could be explained in terms of the interaction of this behavioral regression with different environmental structures, surfaces, and textures.

Finally, Pellis and his colleagues have used the E-W system to examine similarities between elements of human Parkinsonism and the abnormal behavior patterns displayed by rats suffering from LH lesions. Using the E-W system, Pellis, Morrissey, Pellis, and Teitelbaum (1987) noted marked behavioral and pharmacological similarities between the loss of contact righting reflexes in rats with combined LH lesions and labyrinthectomies and the axial apraxia characteristic of severe Parkinsonism in humans.

The examples described in this section demonstrate that the use of a precise descriptive language can reveal common underlying principles of behavioral organization. In ontogeny, in recovery from brain trauma, and following the administration of a drug, across species and at the level of social interaction, the E-W system has revealed cores of behavioral invariance and the hierarchical organization of behavioral subsystems. Findings with such broad generality suggest that the widespread adoption of the $\mathrm{E}-\mathrm{W}$ system will be an invaluable tool for the future generation of ecologically and neurologically valid accounts of behavior.

\section{Implementation of the E-W System}

In the research described above, the common procedure has been to film sequences of behavior and then transcribe them into $\mathrm{E}-\mathrm{W}$ notation by hand. There is one overwhelming obstacle to the widespread use of this method: The manual transcription of a filmed behavioral sequence into movement notation is extremely time-consuming (Hinde, 1970). This problem has forced some investigators to restrict their analysis to the movement of a few limbs, to gross movements only, or to behavior over a short time span. In addition, it has proven difficult to notate more than small sequences of behavior or the behavior of more than a few animals (G. Moran, personal communication, 1985). As a result, it has proven impossible to ensure that the regularities detected in such analyses represent regularities found in the behavior of all the animals of a species. Not surprisingly, some investigators have abandoned movement analysis altogether.

Despite the length of time required to notate behavior by hand, some advocates of the E-W system feel that this is a necessary and important part of its implementation. To many users, the process of notation itself is as important as the creation of a precise behavioral score (I. Golani, personal communication, 1985; G. Moran, personal communication, 1985). Of necessity, hundreds of hours of structured observation are required during which the observer develops both detailed knowledge of the organism under investigation and insights into the organization of its behavior. Although we do not dispute that thoughtful, structured observation is crucial for a full 
understanding of movement or behavior, we do not feel that the analysis of movement need be restricted by cumbersome hand notation.

Computer technology now exists that can record behavior without losing any of its spatial or temporal complexity. These systems use either infrared light-emitting diodes or reflectors placed at the joints of a subject, in combination with an infrared strobe, to construct stickfigure representations of the movement of the subject. In both types of systems, the positions of the joints are detected by two or more video cameras placed at different angles to the subject. These positions are digitized by the computer, which then uses the information to create a representation of the moving organism in the form of a stick figure on a video monitor. When a joint is blocked, ballistic programs are used to interpolate the positions of the missing limbs (Ferrigno \& Pedotti, 1985). Such systems can produce a complete digitized record of a subject's movements.

Calvert and his associates (e.g., Calvert, in press; Calvert, Chapman, \& Patla, 1982) have developed a system that allows a movement notation score to be programmed into a computer and previewed in stick-figure form. This allows choreographers to compose and preview dance and skating routines (e.g., Calvert et al., 1982). I. Golani (personal communication, 1985) has implemented a similar system in which E-W scores are translated into stickfigure representations of the original behavior. As $T$. W. Calvert (personal communication, 1985) has pointed out, it should be a straightforward task to reverse this process so the movement of a subject that has been digitized into stick-figure form can be translated and subsequently analyzed in terms of the E-W movement notation system.

We believe that the integration of computer technology and the E-W system would eliminate many of the problems currently standing in the way of widespread adoption of the E-W system by behavioral researchers. Three advantages strike us as particularly important. First, the computerization of the E-W system would allow the behavior of a relatively large number of subjects to be analyzed at a level of resolution that is impossible with conventional methods of analysis. Using computer technology, sufficient data could be collected and analyzed to ensure the generality of a given behavioral observation-something that is arduous when the E-W system is implemented by hand. Second, having the behavior of an animal captured in a computerized data base would allow for an analysis of all of the frames of reference possible in the E-W system. Once a behavioral sequence is in the data base, different analysis programs could easily be applied to the data to produce E-W scores in each frame of reference. This would allow the researcher to organize easily the subject's behavior from several different perspectives at once-a task that is difficult when E-W is implemented by hand. Third, computerized transcriptions of behavior would allow researchers to easily communicate or publish behavioral data directly and in a standardized format. Schleidt et al.
(1984) proposed that such data could be transposed onto bar strips similar to the universal price codes found on commercial packages. These strips could be published in journals to allow the reader direct access to the data base that the paper is based upon. ${ }^{7}$

The proposed computerization of the E-W system is more than a way of digitizing and storing records of movement. It is an attempt to develop a system for the explicit and formal notation of an organism's behavior, in a manner that will optimize theoretical analysis of that behavior. The initial transcription is not done in E-W notation, nor is the $\mathrm{E}-\mathrm{W}$ system necessary to reap the benefits of formal notation. However, we view the E-W system as integral to this endeavor because it is a language sufficiently rich to capture the full dynamics of movement, yet sufficiently simple to reveal the organizing principles of the complex interactions inherent in behavior.

\section{FINAL OBSERVATIONS}

Here is the psychologist's difficulty. Common sense describes behavior in terms of acts which name effects of behavior on the world-eating dinner, throwing a ball, writing a letter, going to town, welding a ship's plate. But no nerves lead to dinners, to baseballs, to letter paper, to town, or to the plates of a ship. Nerves lead to muscles. It is only movements, not acts, that can be directly explained by the psychologist. (Guthrie \& Edwards, 1949, p. 68)

Each of the authors of this paper has used traditional methods of behavioral investigation. Thus, as is the case with many of our colleagues, our initial reaction to movement-based analyses of behavior was moderate interest, quiet bemusement, and considerable skepticism. However, after reading Golani's (1976) seminal paper on the applications of movement notation to behavior, ${ }^{8}$ we became considerably more wary of our own methods and somewhat less skeptical of movement notation.

As a result, we have argued that the formal methods of behaviorism treat the individual as a dimensionless point and define the behavior of an organism in terms of its consequences. The problem with this system is that it ignores the form of behavior: it acknowledges that an organism can press a lever or run a maze, but is insensitive to the way in which the lever is pressed or the maze is run. This method has provided significant insights into sensory and perceptual organization, and has provided powerful models of learning, memory, cognition, and behavioral ecology. We do not seek to disparage these achievements. However, treating an organism as an idealized point tells us little about the behavior of that organism, sacrificing the very subject of investigation.

On the other hand, we have argued that attempts to recapture the subject matter by observing behavior directly lack the strengths of formal analyses and have introduced problems that leave much of the data uninterpretable. Most observational data are based on taxonomies that lose the spatial and temporal organization of ongoing behavior. More alarmingly, all of the available evidence indicates 
that the elements of intuitively derived behavioral taxonomies are, at best, difficult to recognize, record, or communicate consistently. The "core of invariance" defining the perceptual categories may lie more in the perceptual system of the observer than in the behavior itself.

Behavioral categories are useful to the extent that they conveniently organize behavior, can be consistently recognized, and serve as the basis of valid theory. If other, more simple, more accurate, or more useful behavioral types can be found, then traditional, intuitively derived categories must be abandoned. We should retain only those categories that allow us to detect lawful regularities in the behavioral stream. Those that fail to do so should be left to folk psychology.

We are not pleased with these conclusions. It is as if they were designed to offend the majority of researchers throughout the behavioral sciences. Nevertheless, we see no graceful way to ignore them. Instead, we have suggested that the behavioral sciences could be advanced through the use of a relatively simple tool: formal movement notation. The adoption of a formal system for notating movement represents an important advance in the study of behavior because it allows the physical properties of behavior to be stated objectively and explicitly in a readily communicable form.

None of the formal systems described in this paper provides a complete solution. Each has its own limitations. For example, FACS does not record the movement of the body, whereas the E-W system does not record facial expression. Few formal systems integrate verbal exchange with physical movement, a problem of considerable importance if one is studying human social behavior. However, the use of a formal system allows the researcher to recognize and compensate for these limitations.

Although we advocate the adoption of whatever formal system is most useful for a particular investigation, we are particularly impressed by the E-W system, which is unique in its ability to capture the dynamics of movement, allowing an analysis of both function and morphology. The ability of the E-W system to notate behavior from multiple perspectives has allowed researchers to examine the social interactions of a number of species in ways that reveal organizing principles of behavior that were previously unrecognized. It is particularly intriguing to speculate on the utility of this system in the analysis of complex human behaviors. Although we cannot predict what principles of complex human interactions the E-W system will provide us with, we would be surprised if they were not substantial.

We anticipate considerable debate concerning the role of formal movement notation in the study of behavior. We have already encountered the argument that informal methods of behavioral observation are adequate for some purposes. However, we consider it likely that even in these circumstances a formal method of describing movement would produce a more sensitive and accurate description of the behaviors under study.
Finally, we note that the adoption of a formal language offers only a beginning. No language can guarantee ecologically or neurologically valid units of behavior; those require empirical evidence, careful thought, and theoretical debate. However, by reducing the obstacles posed by a capricious and arbitrary data base, the power of a movement-based approach will be limited not by the ability of the language to describe behavioral regularities but only by the experimental ingenuity and inspired intuitions of those using it.

\section{REFERENCES}

Alley, T. R., \& Shaw, R. E. (198I). Principles of learning and the ecological style of inquiry. Behavioral \& Brain Sciences, 4, 139-140.

BARTON BroWNe, L. (1975). Regulatory mechanisms in insect feeding. Advances in Insect Physiology, 11, 1-116.

Bernays, E. A., \& Simpson, S. J. (1982). Control of food intake. Advances in Insect Physiology, 16, 59-118.

Berridge, K., \& GrILl, H. J. (1983). Alternating ingestive and aversive consummatory responses suggest a two-dimensional analysis of palatability in rats. Behavioral Neuroscience, 97, 563-573.

BirDWhistLe, R. L. (1952). An introduction to kinesics. Louisville: University of Louisville Press.

BoICE, R. (1983). Observational skills. Psychological Bulletin, 93, 3-29. Bolles, R. C. (1967). Theory of motivation. New York: Harper \& Row. BRELAND, K. , \& Breland, M. (1961). The misbehavior of organisms. American Psychologist, 16, 681-684.

Breland, K., \& Breland, M. (1966). Animal behavior. New York: Macmillan.

Brown, P. L., \& JENKINS, H. M. (1968). Auto-shaping of the pigeon's key peck. Joumal of the Experimental Analysis of Behavior, 11, 1-8.

CAlvert, T. (1986). Toward a language for human movement. Computing \& the Humanities, 20, 35-42.

Calvert, T. W., Chapman, J., \& Patla, A. (1982). Aspects of the kinematic simulation of human movement. Computer Graphics \& Applications, 2, 41-50.

Campbell, D. T., STanley, J. C. (1966). Experimental and quasiexperimental designs for research. Chicago: Rand McNally.

Chapple, E. D. (1940). Measuring human relations: An introduction to the study of the interaction of individuals. Genetic Psychology Monographs, 22, 3-147.

CHAPPLE, E. D. (1949). The interaction chronograph: Its evolution and present application. New York: American Management Association.

Chapple, E. D. (1970a). Culture and biological man. New York: Holt, Rinehart \& Winston.

Chapple, E. D. (1970b). Experimental production of transients in human interaction. Nature, 228, 630-633.

Cole, M., Hood, L., \& McDermotT, R. (1982). Ecological niche picking. In U. Neisser (Ed.), Memory observed (pp. 366-374). San Francisco: W. H. Freeman.

Condon, W. S. (1977). A primary phase in the organization of infant responding behavior. In H. R. Schaffer (Ed.), Studies in mother-infant interaction: Proceedings of the Loch Lomond symposium, Ross Priory, University of Strathclyde, September, 1975 (pp. 153-176). London: Academic Press.

Condon, W. S. (1979). Neonatal entrainment and enculturation. In M. Bullowa (Ed.), Before speech: The beginning of interpersonal communication (pp. 131-148). Cambridge: Cambridge University Press.

Condon, W. S., \& Brosin, H. W. (1969). Micro linguistic-kinesic events in schizophrenic behavior. In D. V. S. Sankar (Ed.), Schizophrenia: Current concepts and research (pp. 812-837). Hicksville, NY: PJD Publications.

Condon, W. S., \& OGSTON, W. D. (1966). Sound film analysis of normal and pathological behavior patterns. Joumal of Nervous and Mental Disease, 143, 338-347.

Condon, W. S., \& OGSTON, W. D. (1967). A segmentation of behavior. Journal of Psychiatric Research, 5, 221-235.

Condon, W. S., \& SANDER, L. W. (1974). Neonate movement is syn- 
chronized with adult speech: Interactional participation and language acquisition. Science, 183, 99-101.

Craig, K. D., \& Patrick, C. J. (1985). Facial expression during induced pain. Joumal of Personality \& Social Psychology, 48, 1080-1091.

Craig, K. D., \& Prkachin, K. M. (1983). Nonverbal messages of pain. In R. Melzack (Ed.), Pain measurement and assessment. New York: Raven Press.

DARWIN, C. (1872). The expression of the emotions in man and animals. London: Murray.

DAVIS, B. D. (1984). Objectivity versus doctrine. Nature, 311, 294.

DeMaster, B., ReID, J., \& Twentyman, C. (1977). The effects of different amounts of feedback on observers' reliability. Behavior Therapy, 8, 317-329.

Dethier, V. G. (1976). The hungry fly. Cambridge, MA: Harvard University Press.

DewsBURY, D. A. (1978). Comparative animal behavior. New York: McGraw-Hill.

Doman, M. (1984). Biological constraints and the pursuit of general theories of learning. In R. L. Mellgren (Ed.), Animal cognition and behavior (pp. 319-344). Amsterdam: North-Holland.

Domuan, M., \& Galef, B. G., JR. (1983). Constraints on instrumental and classical conditioning: Retrospect and prospect. Animal Learning \& Behavior, 11, 151-161.

EIBL-EIBesFe LDT, I. (1972). Ethology: The biology of behavior. Toronto: Holt, Rinehart \& Winston.

EiBl-EIBESFELDT, I. (1979). Human ethology: Concepts and implications for the sciences of man. Behavioral \& Brain Sciences, 2, 1-58.

EISEnberG, J. F., \& Golani, I. (1976). Communication metatheria. In T. A. Seboek (Ed.), How do animals communicate? Bloomington: Indiana University Press.

EKman, P. (1972). Universals and cultural differences in facial expressions of emotion. In J. K. Cole (Ed.), Nebraska Symposium on Motivation. Lincoln: University of Nebraska Press.

Ekman, P. (1973). Cross-cultural studies of facial expression. In P. Ekman (Ed.), Danwin and facial expression: $A$ century of research in review. New York: Academic Press.

EKMAN, P., \& FrIESEN, W. (1968). Nonverbal behavior in psychotherapy research. In J. Shlien (Ed.), Research in psychotherapy (Vol. 3). Washington, DC: American Psychological Association.

Ekman, P., \& Friesen, W. (1969). The repertoire of nonverbal behavior: Categories, origins, usage, and coding. Semeiotics, 1, 49-98.

Ekman, P., \& FrIesen, W. (1971). Constants across cultures in the face and emotion. Journal of Personality \& Social Psychology, 17, 124-129.

Ekman, P., \& Friesen, W. (1975). Unmasking the face: A guide to recognizing emotion from facial clues. Englewood Cliffs, NJ: Prentice-Hall.

Ekman, P., Friesen, W. (1978a). Facial Action Coding Scheme (FACS): A technique for the measurement of facial action. Palo Alto, CA: Consulting Psychologists Press.

EKman, P., \& FrIESEN, W. (1978b). Investigators guide to the Facial Action Coding Scheme. Palo Alto, CA: Consulting Psychologists Press.

EKMAN, P., \& FrIEsEN, W. (1978c). Manual for the Facial Action Coding Scheme. Palo Alto, CA: Consulting Psychologists Press.

EshKol, N., \& WAHMAN, A. (1958). Movement notation. London: Weidenfeld \& Nicolson.

FARKaS, G. M., ThaRP, R. G. (1980). Observation procedure, observer gender, and behavior valence as determinants of sampling error in a behavioral assessment analogue. Journal of Applied Behavior Analysis, 13, 529-536.

Fentress, J. C. (1984). The development of coordination. Journal of Motor Behavior, 16, 99-134.

Ferrigno, G., \& Pedotti, A. (1985). ELITE: A digital dedicated hardware system for movement analysis via real-time TV signal processing. IEEE Transactions of Biomedical Engineering, 11, 943-949.

Fisch, H., Frey, S., \& HisbrunNer, H. (1983). Analyzing nonverbal behavior in depression. Journal of Abnormal Psychology, 92, 307-318.

Garcia, J., Rusiniak, K. W., B Brett, L. P. (1977). Conditioning food-illness aversions in wild animals: Caveant canonici. In H. Davis \& H. B. Hurwitz (Eds.), Operant-Pavlovian interactions (pp. 273317). Hillsdale, NJ: Erlbaum.
GolANI, I. (1976). Homeostatic motor processes in mammalian interactions: A choreography of display. In P. P. G. Bateson \& P. H. Klopfer (Eds.), Perspectives in ethology (Vol. 2). New York: Plenum Press.

Golani, I., Bronchti, G., Moualem, D., \& Teitelbaum, P. (1981). "Warm-up" along dimensions of movement in the ontogeny of exploration in rats and other infant mammals. Proceedings of the $\mathrm{Na}$ tional Academy of Science (U.S.A.), 78, 7226-7229.

GolANI, I., \& FENTRESS, J. (1987). Early ontogeny of face grooming in mice. Manuscript submitted for publication.

Golani, I., Wolgin, D. L., \& Teitelbaum, P. (1979). A proposed natural geometry of recovery of function from akinesia in the lateral hypothalamic rat. Brain Research, 164, 237-267.

GotTLEB, G. (1976). The roles of experience in the development of behavior and the nervous system. In G. Gottlieb (Ed.), Neural and behavioral specificity (pp. 25-54). New York: Academic Press.

GouLD, J. L. (1982). Ethology: The mechanisms and evolution of behavior. New York: Norton.

Gould, S. J. (1985). Taxonomy of death (review of M. H. Niticki [Ed.], Extinctions). Nature, 313, 505-506.

GRAY, J. A. (1982). The neuropsychology of anxiety. New York: Oxford University Press.

GrILL, H. J., \& BERRIDGE, K. C. (1985). Taste reactivity as a measure of the neural control of palatability. In J. M. Sprague \& A. N. Epstein (Eds.), Progress in psychobiology and physiological psychology (Vol. 11, pp. 1-61). New York: Academic Press.

GrILL, H. K., \& NorGREN, R. (1978). Taste reactivity test: I. Mimetic responses to gustatory stimuli in neurologically normal rats. Brain Research, 143, 263-279.

GuTHRIE, E. R., \& EDWARDS, A. L. (1949). Psychology: A first course in human behavior. New York: Harper.

HARRIS, F. C., \& LAHEY, B. B. (1982). Recording system bias in direct observational methodology: A review and critical analysis of factors causing inaccurate coding behavior. Clinical Psychology Review, 2, 539-566.

Helmchen, H., \& Renfordt, E. (1981). The contribution of audiovisual techniques to advances in psychopathology. Comprehensive Psychiatry, 22, 21-30.

HiLL, D. (1974). Non-verbal behaviour in mental illness. British Journal of Psychiatry, 124, 221-230.

HINDE, R. A. (1959). Some recent trends in ethology. In S. Koch (Ed.), Psychology: A study of science (Vol. 2, pp. 561-610). New York: McGraw-Hill.

HINDE, R. A. (1970). Animal behaviour: A synthesis of ethology and comparative psychology. Toronto: McGraw-Hill.

HiNDE, R. A. (1982). Ethology: Its nature and relations with other sciences. New York: Oxford University Press.

HopkINs, B. (1983). The development of early non-verbal communication: An evaluation of its meaning. Journal of Child Psychology \& Psychiatry, 24, 131-144.

Hoy Le, G. (1984). The scope of neuroethology. Behavioral \& Brain Sciences, 7, 367-412.

JenkINs, H. M., Moore, B. R. (1973). The form of the auto-shaped response with food or water reinforcers. Joumal of the Experimental Analysis of Behavior, 20, 163-181.

Johnston, T. P. (1981). Contrasting approaches to a theory of learning. Behavioral \& Brain Sciences, 4, 125-173.

Jones, R. R., Reid, J. B., \& Patterson, G. R. (1974). Naturalistic observation in clinical assessment. In P. McReynolds (Ed.), Advances in psychological assessment (Vol. 3). San Francisco: Jossey-Bass.

KENT, R. N., \& Foster, S. L. (1977). Direct observational procedures: Methodological issues in naturalistic settings. In A. R. Ciminero, K. S. Calhoun, \& H. E. Adams (Eds.), Handbook of behavioral assessment. New York: Wiley.

Kent, R. N., Kanowttz, J., O'Leary, K. D., \& Cheiken, M. (1977). Observer reliability as a function of circumstances of assessment. Journal of Applied Behavior Analysis, 10, 317-324.

Kent, R. N., O'Leary, K. D., Diament, C., \& Dietz, A. (1974). Expectation biases in observational evaluation of therapeutic change. Joumal of Consulting \& Clinical Psychology, 42, 774-780.

Kent, R. N., O'Leary, K. D., Dietz, A., \& Diament, C. (1979). A comparison of observational recordings in vivo, via mirror and via television. Journal of Applied Behavior Analysis, 12, 517-522. 
Kolb, B., Jacobs, W. J., \& Petrie, B. (1987). Searching for a technology of behavior. Behavioral \& Brain Sciences, 10, 220-221.

KoNORSKI, J. (1967). Integrative activity of the brain. Chicago: University of Chicago Press.

LASHLEY, K. S. (1952). Functional interpretation of anatomical patterns. Proceedings, Association for Research in Nervous \& Mental Diseases, 30, 529-547.

LeResche, L., \& Dworkin, S. F. (1984). Facial expression accompanying pain. Social Science \& Medicine, 19, 1325-1330.

LONGABAUGH, R. (1980). The systematic observation of behavior in naturalistic settings. In H. C. Triandis \& J. W. Berry (Eds.), Handbook of cross-cultural psychology (pp. 57-125). Toronto: Allyn \& Bacon.

Lorenz, K. (1950). The comparative method in studying innate behaviour patterns. Symposium of the Society for Experimental Biology, 4, 221-268.

Lorenz, K. (1974). Analogy as a source of knowledge. Science, 185, 229-234.

LORENZ, K., \& TiNBERGEN, N. (1970). Taxis and instinctive behavior pattern in egg-rolling by the greylag goose. In K. Lorenz \& R. Martin (Ed. and Trans.), Studies in animal and human behavior (Vol. 1, pp. 316-350). Cambridge, MA: Harvard University Press. (Original work published 1938)

MacCorquodale, K., \& Meehl, P. E. (1954). Edward C. Tolman. In A. T. Poffenberger (Ed.), Modem learning theory (pp. 177-266). New York: Appleton-Century-Crofts.

MACKAY, D. M. (1972). Formal analysis of communicative processes. In R. A. Hinde (Ed.), Non-verbal communication (pp. 3-25). Cambridge: Cambridge University Press.

Marshall, J. F., Richardson, J. S., \& Teitelbaum, P. (1974). Nigrostriatal bundle damage and the lateral hypothalamic syndrome. Journal of Comparative \& Physiological Psychology, 87, 808-830.

Marshall, J. F., Turner, B. H., \& Teitelbaum, P. (1971). Sensory neglect produced by lateral hypothalamic damage. Science, 174, 523-525.

Mash, E. J., \& Makohonjuk, G. (1975). The effects of prior information and behavioral predictability on observer accuracy. Child Development, 46, 513-519.

MASH, E. J., \& McELwEE, J. D. (1974). Situational effects on observer accuracy: Behavior predictability, prior experience, and complexity of coding categories. Child Development, 45, 367-377.

Mrtchell, P. C. (1911). The childhood of animals. New York: Stokes.

Mogenson, G. J., \& PHILlips, A. G. (1976). Motivation: A psychological construct in search of a physiological substrate. In J. M. Sprague \& A. N. Epstein (Eds.), Progress in psychobiology and physiological psychology (Vol. 6, pp. 189-243). New York: Academic Press.

Moore, B. R. (1973). The role of directed Pavlovian reactions in simple instrumental learning in pigeons. In R. A. Hinde \& J. StevensonHinde (Eds.), Constraints on learning (pp. 159-186). New York: Academic Press.

Moran, G., Fentress, J. C., \& Golani, I. (1981). A description of relational patterns of movement during "ritualized" fighting in wolves and dogs. Animal Behaviour, 29, 1146-1165.

Nashner, L. M., \& McCollum, G. (1985). The organization of human postural movements: A formal basis and experimental synthesis. Behavioral \& Brain Sciences, 8, 135-172.

OPPENheim, N. (1898). The development of the child. New York: Macmillan.

OPPENhEIm, R. W. (1980). Metamorphosis and adaptation in the behavior of developing organisms. Developmental Psychobiology, 13, 353-356.

Pansa-Henderson, M., de L'Horne, D. J., \& Jones, I. H. (1982). Nonverbal behaviour as a supplement to psychiatric diagnosis in schizophrenia, depression, and anxiety neurosis. Joumal of Psychiatric Treatment \& Evaluation, 4, 489-496.

Pelchat, M. L., Grill, H. J., Rozin, P., \& Jacobs, J. (1983). Quality of acquired responses to tastes by Rattus norvegicus depends on type of associated discomfort. Behavioral Neuroscience, 97, 140-153.

Pelchat, M. L., \& Rozin, P. (1982). The special role of nausea in the acquisition of food dislikes by humans. Appetite, 3, 341-351.
Pelus, S. M. (1981). A description of social play by the Australian magpie Gymnorhiwa tibicen based on Eshkol-Wachman notation. Bird Behaviour, 3, 61-79.

Pellis, S. M. (1982). An analysis of courtship and mating in the Cape Barren goose Cereopsis novachollandiae based on the EshkolWachman movement notation. Bird Behaviour, 4, 30-41.

Pellis, S. M., Morrisey, T. K., Pellis, V. C., \& Teitelbaum, P. (1987). Fractionation of the subcomponents and transmitter controls of contact-righting in labyrinthectomized lateral hypothalamic-damaged rats. Society for Neuroscience Abstracts, 13, 405.

Pfaus, J. G., Blackburn, J. R., Harpur, T. J., MacDonald, M. A., MANA, M. J., \& JACOBS, W. J. (in press). Has psychology ever been a science of behavior? A comment to Skinner. American Psychologist.

Pinel, J. P. J., \& TREIT, D. (1978). Burying as a defensive response in rats. Journal of Comparative \& Physiological Psychology, 92, 708-712.

Redfield, J., \& PaUL, G. L. (1976). Bias in behavior observation as a function of observer familiarity with subjects and typicality of behavior. Journal of Consulting \& Clinical Psychology, 44, 156.

REID, J. B. (1970). Reliability assessment of observation data: A possible methodological problem. Child Development, 41, 1143-1150.

RomanczyK, R. G., Kent, R. N., Diament, C., \& O'Leary, K. D. (1973). Measuring the reliability of observational data: A reactive process. Joumal of Applied Behavior Analysis, 6, 175-184.

Rozin, P., \& Kalat, J. W. (1971). Specific hungers and poison avoidance as adaptive specializations of learning. Psychological Review, 78, 459-486.

SATINOFF, E. (1982). Are there similarities between thermoregulation and sexual behavior? In D. Pfaff (Ed.), Physiological mechanisms of motivation (pp. 217-251). New York: Springer-Verlag.

SChleidt, W. M., Yakalis, G., Donnelly, M., \& McGarRy, J. (1984). A proposal for a standard ethogram, exemplified by an ethogram of the bluebreasted quail (Cotumix chinensis). Zeitschrift für Tierpsychologie, 64, 193-220.

SheTtLeworTH, S. J. (1972). Constraints on learning. In D. S. Lehrman, R. A. Hinde, \& E. Shaw (Eds.), Advances in the study of behaviour (Vol. 4, pp. 1-68). New York: Academic Press.

SHETTLEWORTH, S. J. (1983a). Function and mechanism in learning. In M. D. Zeiler \& P. Harzem (Eds.), Biological factors in learning (pp. 1-39). Toronto: Wiley.

SheTtLewORTH, S. J. (1983b). Memory in food-hoarding in birds. Scientific American, 248, 102-110.

Shuller, D. Y., \& McNamara, J. R. (1976). Expectancy factors in behavioral observation. Behavior Therapy, 7, 519-527.

Simpson, S. J., \& BERNAYs, E. A. (1983). The regulation of feeding: Locusts and blowflies are not so different from mammals. Appetite: Joumal for Intake Research, 4, 313-346.

SKINNER, B. F. (1938). The behavior of organisms. New York: Appleton-Century-Crofts.

SKINNER, B. F. (1953). Science and human behavior. New York: Macmillan.

Spencer-Brown, G. (1979). Laws of form. New York: Dutton.

Szechtman, H., Ornstein, K., Hofstein, R., Teitelbaum, P., \& GolaNI, I. (1980). Apomorphine induces behavioral regression: A sequence that is the opposite of neurological recovery. In E. Usdin, T. L. Sourkes, \& M. B. H. Youdim (Eds.), Enzymes and neurotransmitters in mental disease (pp. 511-517). New York: Wiley.

Szechtman, H., Ornstein, K., Teitelbaum, P., \& Golani, I. (1985). The morphogenesis of stereotyped behavior induced by the dopamine receptor agonist apomorphine in the laboratory rat. Neuroscience, 14, 783-798.

Taplin, P. S., \& Reid, J. B. (1973). Effects of instructional set and experimenter influence on behavior reliability. Child Development, 44, 547-554.

Tertelbaum, P. (1986). The lateral hypothalamic double-disconnection syndrome: A reappraisal and a new theory for recovery of function. In S. H. Hulse \& B. F. Green, Jr. (Eds.), One hundred years of psychological research in America: G. Stanley Hall and the Johns Hopkins tradition (pp. 79-124). Baltimore, MD: Johns Hopkins University Press.

Teitelbaum, P., Schallert, T., \& Whishaw, I. Q. (1983). Sources 
of spontaneity in motivated behavior. In E. Satinoff \& P. Teitelbaum (Eds.), Handbook of behavioral neurobiology (Vol. 6, pp. 23-65). New York: Plenum Press.

Tinbergen, N. (1951). The stucty of instinct. New York: Oxford University Press.

Tingergen, N., \& KRUYT, W. (1938). Über die Orientierung des Bienenwolfes (Philanthus triangulum): III. Die Bevorzugung bestimmter Wegmarken. Zeitschrift für Vergleichende Physiologie, 25, 292-334.

Tolman, E. C. (1932). Purposive behavior in animals and men. New York: Appleton Century.

UTTAL, W. R. (1978). The psychobiology of mind. New York: Erlbaum.

WATsoN, J. B. (1928). What the nursery has to say about instincts. In C. Murchison (Ed.), Psychologies of 1925 (pp. 1-36). Worcester, MA: Clark University Press.

Whitehead, A. N. (1929). Process and reality: An essay in cosmology. Gifford Lectures, Edinburgh, 1927-1928. Cambridge: Cambridge University Press.

Wildman, B. G., Erickson, M. T., \& Kent, R. N. (1975). The effect of two training procedures on observer agreement and variability of behavior ratings. Child Development, 46, 520-524.

Williams, D. R., \& Williams, H. (1969). Automaintenance in the pigeon: Sustained pecking despite contingent non-reinforcement. Journal of the Experimental Analysis of Behavior, 12, 511-520.

World Health Organization. (1983). Diagnosis and classification of mental disorders and alcohol- and drug-related problems: A research agenda for the 1980s. Psychological Medicine, 13, 907-921.

YouNG, P. T. (1966). Hedonic organization and regulation of behavior. Psychological Review, 72, 59-86.

\section{NOTES}

1. For technical reasons, we find the terms type and token more accurate than act and movement. These reasons will be discussed later in the paper.

2. In addition, the system of categorization began to break down within its definition. For example, Brown and Jenkins (1968) discovered that a classically defined operant, the keypeck, seemed to obey Pavlovian rather than operant nules (see also Jenkins \& Moore, 1973; Moore, 1973; Williams \& Williams, 1969). We note that many of the "failures" of these operant rules are found when the definition is ignored (e.g., Breland \& Breland, 1966; Brown \& Jenkins, 1968). That, however, is another story.

3. Our argument can be stated another way. The types of behavior used in most areas of behavioral science may tell us a great deal about human concept formation and ideology, but they are not accurate reflections of the actual world. Because of this, our attempts to build theories of "behavior" have failed to produce any general theory or paradigm. Many elegant theories have been developed within paradigms, but in every case their field of applicability has been depressingly small. In effect, our explanations of "behavior" have been explanations of what humans think behavior is.

4. There may be alternative methods of describing behavior which are equally explicit but not based in movement. For example, students of the feeding of locusts and blowflies have been successful in describing appetitive behavior in terms of spatial and temporal parameters such as intermeal interval, meal size, diel rhythmicity, short-term rhythmicity, and time in proximity to food source. The physiological and anatomical mechanisms that underlie the observed behavioral regularities are being investigated. When such mechanisms are found, hypothesized behavioral organization is validated. When they are not, the behavioral taxonomy is discarded and an alternative one is pursued. (For recent reviews, see Barton Browne, 1975; Bernays \& Simpson, 1982; Dethier, 1976; Simpson \& Bernays, 1983.)

On another level, behavioral taxonomies such as that proposed by Nashner and McCollum (1985) may be of value. They present a formal biomechanical system that is used to generate hypotheses about the neurological basis of human postural maintenance. Their scheme permits integration of sensory information and contractile patterns, and when certain explicit assumptions about the pattern of muscle contractions are met, rigidly specified predictions about behavior emerge. Although this system is progressive in that it integrates neurophysiology and behavior, it does not yet have sufficient scope to accommodate analyses of complex behavior such as social actions.

5. Hill (1974) points out that experienced psychiatrists of an earlier generation used nonverbal behavior as part of the diagnostic procedure. They noted not only "the more bizarre postures, gestures and disorders of motility of severe chronic mental illness," but also "the slow movements, flexed posture, diminished motility and lack of spontaneous and associative movements, the immobile facial expression of the retarded depressive; the decreased or restricted general motility but increased peripheral movements of the agitated depressive; the rigid bodily postures and precise movements of the tense obsessional; the protracted handshake, the searching looks, the persistent eye-to-eye contact of the paranoid; and the lack of these and the failure to adopt congruent postures and to make congruent movements of the schizophrenic" (p. 227).

6. There have been several adaptations of the E-W Movement Notation system. The description of the notation system here is based on Golani (1976), Golani et al. (1981), and Szechtman et al. (1985).

7. Access to a reconstruction of the behavior under consideration would allow anyone to perform either formal or informal analyses of the data. However, for adequate communication to other researchers, it would be necessary to produce software that could be used by others to perform similar analyses. Such a situation has proved beneficial in other areas of psychology (e.g., in formal modeling of cognitive processes) because it has forced researchers to test the assumptions and implications of their taxonomies explicitly. This does not stifle intuition, but does encourage conceptual clarity.

8. This paper is an exciting and elegant presentation of the principles, advantages, and successes of the application of $E-W$ notation to behavioral analysis. Any reader who finds the ideas presented here of more than passing interest is urged to turn to this source.

(Manuscript received July 2, 1987; revision accepted for publication January $13,1988$. 